\title{
Don Quijote y el Oidor de México: desencuentro de caballeros
}

\author{
María Eugenia MaYer*
}

«¿Yo no caballero? [...] mientes

[...] [dijo el escudero vizcaíno]». $(\mathrm{I}, 8)$

[Don Quijote] hubo de callar y estarse quedo, esperando a ver en qué paraban las diligencias de aquellos [...].

— Sepamos qué es esto de raíz- dijo a este tiempo el oidor. (I, 39)

El origen del Quijote de 1605 es el Relato del Cautivo (I, 39-41), según el editor Luis Andrés Murillo ${ }^{1}$. Redactado en 1590, año en que se le niega a Cervantes el paso a Indias por segunda vez, el relato interrumpe el discurso de Don Quijote sobre las armas y las letras, y presenta al leguleyo Juan Pérez de Viedma, que «iba proveído por oidor [a] la Audiencia de Méjico», un caballero moderno que hace auditorías, ha heredado de tres parientes y sabe deshacer los entuertos que afectan a su cargo. Es la antítesis del hidalgo manchego,

* Pasadena City College.

1. Murillo, Luis A., «El Ur-Quijote, nueva hipótesis», Cervantes, 1, 1981, pp. 42-50. Cervantista de establecida trayectoria internacional y editor del Quijote, Murillo reafirma en su edición para Castalia que la fecha de composición del Relato «antecede a la de lo demás del Quijote de 1605 y de las primeras novelas ejemplares» $\left(\mathrm{n}^{\circ}{ }^{\mathrm{o}} 1\right)$, aseveración que sustenta por medio del contraste entre biografismos cervantinos, fechas de publicación de libros mencionados en la biblioteca de don Quijote, y argumentos de varios tipos. Cervantes Saavedra, Miguel de, El ingenioso hidalgo don Quijote de la Mancha, Luis A. Murillo (ed.), 5. a ed., 2 vol., Madrid, Castalia, 1987. Ha habido otras hipótesis sobre la génesis del Quijote, aunque no de tanto poder explicativo, a mi entender, como la de Murillo. Las presenta nítidamente José Manuel Martín Morán y avanza en la interesante hipótesis sobre «la génesis teatral de ciertos episodios de la novela» en El Quijote en ciernes. Los descuidos de Cervantes y las fases de la elaboración textual, Turín, Edizioni dell Orso, 1990. «La argumentación [de Morán] sobre la novela del cautivo y su posible origen teatral es plausible, pero menos convincente [que sobre otros episodios]», señala José Montero Reguera en El Quijote y la crítica contemporánea, Madrid, Centro de Estudios Cervantinos, 1997, p. 147. 
[...] había salido del coche un hombre que, en el traje mostró luego el oficio y cargo que tenía [...]. Hallóse don Quijote al entrar del oidor [...] y, así como le vio, dijo: «seguramente puede vuestra merced entrar y espaciarse en este castillo, que, aunque es estrecho y mal acomodado, no hay estrecheza ni hay incomodidad en el mundo que no dé lugar a las armas y a las letras $[\ldots] \gg .(I, 42)$

quien se quedará en el preámbulo del discurso. Mediante componendas aisladas, el letrado intenta casar a su hija con un noble heredero y llevárselo a México. Entre «los inauditos sucesos de la venta» (epígrafe de I, 44), uno de éstos es un caso no-audito literalmente:

[...] [Don Quijote] hubo de callar y estarse quedo, esperando a ver en qué paraban las diligencias de aquellos [...].

- Sepamos qué es esto de raíz - dijo a este tiempo el oidor.

Pero el hombre, que lo conoció, como vecino de su casa, respondió:

- ¿No conoce vuestra merced, señor oidor, a este caballero, que es el hijo de su vecino $[\ldots]$ ?

Miróle entonces el oidor más atentamente y conocióle [...].

El oidor dijo [...] que se sosegasen, que todo se haría bien; y tomando por la mano a don Luis, le apartó a una parte y le preguntó qué venida [era ésta] [...] volvámonos atrás cincuenta pasos [...] a ver qué fue lo que [Don Luis] [...] respondió al oidor (I, 44; énfasis añadido)

No se nos deja escuchar nada del aparte. Pérez de Viedma es un caballero de las «letras» de auditoría, de los que prosperaban a la sombra sevillana del Real Consejo de las Indias y la Casa de Contratación, del tráfico de mercancías, información y personas. Cervantes tuvo oportunidad de avistar esos círculos tanto en Sevilla como en la corte vallisoletana.

Están por terminar los fechos y discursos del hidalgo, enjaulado de vuelta al pueblo. El cura «licenciado» (así llamado doce veces en tres capítulos) ${ }^{2}$ y el barbero despiden a Ruy y a hermano oidor (I, 47). La «verdadera historia» anuncia desde el prólogo la intención de erradicar la credulidad respecto a

2. Capítulos 5, 26 y 29 de la parte I, insistencia que continuará en el capítulo 1 de la parte II:

¿Qué le parece a vuestra merced, señor licenciado Pero Pérez — que así se llamaba el cura - de la desgracia de mi señor? [...] el cura se informó muy a la larga [...] del modo que había hallado a don Quijote que fue poner más deseo en el licenciado [de] llamar a su amigo el barbero. (I, 5; énfasis añadido)

[...] salieron de la venta dos personas [...] y dijo el uno al otro: dígame, señor licenciado, ¿aquél del caballo no es Sancho Panza? [...]. Sí es, dijo el licenciado, y aquél es el caballo de nuestro Don Quijote; y conociéronle tan bien como aquellos que eran, el cura y el barbero de su mismo lugar. (I, 26; énfasis añadido)

$\mathrm{Y}$ antes que ella respondiese, dijo el licenciado [así es llamado el cura ocho veces, nada menos, en este capítulo]:

[...] ¿Hacia qué reino quiere guiar la vuestra señoría? ¿Es, por ventura, hacia el de Micomicón [de esclavos negros]? Que sí debe de ser, o yo sé poco de reinos.

Ella, que estaba bien en todo, entendió que había que responder que sí. (I, 29) 
los libros de caballerías y pone fin a las del enloquecido manchego, mientras encauza las sensatas caballerías del letrado a un futuro indiano. Así refuerza el contraste entre el de la Triste Figura y el caballero que parte a Indias a figurar.

El desencuentro entre caballeros abre y cierra la obra. En su primera aventura, el manchego ve a una dama «cautiva» que «iba a Sevilla, donde estaba su marido, que pasaba a Indias con un muy honroso cargo» y, queriendo rescatarla, embiste contra su escolta, quien le echa en cara su desfase respecto a las caballerías: «¿Yo no caballero? [...] mientes» (I, 8). El último episodio muestra al hidalgo «quedo [a]l entrar del oidor» quien también va a América vía Sevilla. Al final se repite la escena apertural («aquella buena señora que allí va cautiva», I, 52) e incluso sus frases (el «iAgora veredes!» de I, 9); pero no hay aventura: don Quijote queda «captivado» mientras el caballero burócrata parte hacia América.

Por medio del contraste entre caballeros se despliega ante el público de la venta, y ante el lector, el cambio surgido en el imperio hispano: de África y el lar mediterráneo a la América transoceánica; del medioevo a la modernidad; de la empresa religiosa y guerrera a la comercial y política; del caballero peninsular, epítome de la acción, al caballero indiano y escribano; y del documento inédito sobre la participación del soldado Saavedra en la gesta de $\mathrm{La}$ Goleta, al Relato del Cautivo y al Ingenioso Hidalgo. El caballero anticuado ha sido reemplazado por un caballero de Indias de ingenio adaptado a la era del valido Lerma. Así lo entiende el plagiario del Quijote, Avellaneda, cuando se jacta de robarle la ganancia al Manco: «No le parecerán [ingeniosas] las razones desta historia, que se prosigue con la autoridad que él la comenzó, y con la copia de fieles relaciones que a su mano llegaron[...] $\rangle^{3}$.

El Relato del Cautivo fue una relación de hechos sobre el cautiverio de un Ruy Pérez de Viedma. Insta al lector discreto a que esté «tan atento» al «negocio» de su entorno como lo está el Viedma de la audiencia novohispana, quien oirá casos y los consultará:

[...] [el Oidor] no sabía [qué decisión] tomar en tan repentino y no esperado negocio; y así no respondió otra cosa sino que se sosegasen [...] porque se tuviese tiempo para considerar lo que mejor a todos estuviese [...] el oidor, que, como discreto, ya había conocido cuán bien le estaba a su hija aquel matrimonio [...] si fuera posible, lo quisiera efectuar con voluntad del padre de don Luis, del cual sabía que pretendía hacer de título a su hijo. $(I, 44)^{4}$

3. Fernández de Avellaneda, Alonso, El ingenioso hidalgo don Quijote de la Mancha, que contiene su tercera salida y es la quinta parte de sus aventuras, Tarragona, 1614. Para el apócrifo, utilizo la edición de Fernando García Salinero (Madrid, Castalia, 1987).

4. Era asunto delicado, para el Oidor, el pasar a su futuro yerno a Indias, pues «[1]a legislación indiana especificaba que [...] los nacidos en América debían ocupar con prioridad los empleos del virreinato y ser los únicos beneficiarios de las rentas del país». Este estudio de la profesora Latasa, de la Universidad de Navarra, se enfoca en los años del Quijote. Latasa Vassallo, Pilar, «¿Criollismo peruano vs. Administración española? Posición criollista del virrey Montesclaros (1607-1615)», en 
Puestos, pues, ya en sosiego, y hechos amigos todos a persuasión del oidor y del cura, volvieron los criados de don Luis a porfiarle que al momento se viniese con ellos; y en tanto que él con ellos se avenía, el oidor comunicó con don Fernando, Cardenio y el cura qué debía hacer en aquel caso, contándoseles con las razones que don Luis le había dicho. (I, 45) ${ }^{5}$

Los Viedma confían en las tercerías del sagaz cura, congregador de lectores y rescatador de manuscritos anónimos. Se va revelando el círculo del poder imperial en sus dos brazos: el secular y el religioso («[así] fue prosiguiendo el cura [...] a todo lo cual estaba tan atento el oidor, que ninguna vez había sido tan oidor como entonces»; I, 42). El hombre en ropas de moro despliega su historia y el cura — que ha recibido buen dinero desde Indias (I, 29) - la lima ortodoxamente ante el Oidor. Este sigue su ruta hacia México, habiendo conocido al hidalgo de «humor extraño» (I, 43) y aplacado con dineros a la Santa Hermandad (I, 46). Llegará a buen puerto la historia del Cautivo, núcleo del Quijote, y la del «Saavedra [cuyos hechos] quedarán en la memoria de aquellas gentes» (I, 40), aun antes de que F. Diego de Haedo logre publicar la Relación de las cosas de Argel o Topographia de Argel (aprobada en 1604, sólo sale a luz, tras la firma del cronista Antonio de Herrera y Tordesillas, en 1612).

No «todo es comedia» en el Quijote, como dice el prólogo del apócrifo, pero el relato permitió a Cervantes demostrar escénicamente - con entretelones y ruidos que distraen tras bambalinas - que para que un escrito novel y significativo circulara, se tratase de libro o documento, antes había que aprender los protocolos de la comunicación mediada, la que conlleva tercerías. Lo que parte con el Oidor hacia Indias es una escritura posible e ingeniosa. Por magia del Manco, el Quijote se transforma en una complicidad de lectura, en el proyecto de zanjar un océano y abrirle al aprendiz-lector un mundo bivalvo.

Cervantes reconoció en las letras hispanas la dimensión bicostera que tuvieron desde el encuentro de dos mundos en el siglo XV, a partir de la Carta del Descubrimiento y de la subsecuente crónica de Indias. Este fenómeno bicostero alcanza a nuestra era.

La orientación americana del cervantismo se inició con el peruano Ricardo Palma («Sobre el Quijote en América», 1906, dedicado a Unamuno e impreso en Barcelona) y el español Francisco Rodríguez Marín (El Quijote y Don Quijote en América, 1911) ${ }^{6}$. En 1905, tricentenario de la obra, salen los Cantos de vida y esperanza de Darío, reclamo latino-americano de la identidad hispana

I Congreso Internacional de peruanistas en el extranjero [en línea], disponible en 〈http://www.fas. harvard.edu/ icop/pilarlatasa.html .

5. El plan original de irse a Sevilla los hermanos Viedma y Zoraida (I, 43) ha sido abandonado inexplicablemente; pero es un vacío textual sobre el que se da una sola pista: quien sí se irá con el Oidor y pasará a América es don Luis, futuro «título».

6. Valero Juan, Eva M. ${ }^{a}$ (comp.), El Quijote en América. Antología de ensayos críticos [en línea], Centro Virtual Cervantes, 2006, disponible en «http://cvc.cervantes.es/obref/quijote_america/ peru/palma.html>. 
por medio del Quijote, y la novela del venezolano Tulio Febres Cordero, Don Quijote en América. La guerra de 1898 entre EE.UU. y España, encauzó al cervantismo hacia América y a los hispanoamericanos hacia el Quijote. Pusieron la piedra angular de la tendencia el chileno José Toribio Medina («Cervantes americanista», 1915) y el dominicano Pedro Henríquez Ureña («De la nueva interpretación del Quijote», 1916). La venezolana Teresa de la Parra cultivó el cervantismo americanista en Ifigenia (1924), novela que alude a la teatralidad del Quijote y a su mensaje sobre el escritor subalterno ${ }^{7}$.

El nexo entre América y Cervantes siguió captando adeptos después de la II Guerra Mundial. En los años 60, José de Mesa publicó «América en la obra de Cervantes», ensayo consignado por Guillermo Díaz-Plaja (Don Quijote en el país de Martín Fierro) y Jorge Albistur, Stelio Cro y Hugo Rodríguez Vecchini señalaron el vínculo narrativo entre el Inca y el Manco. Hoy en día, el cervantismo avanza en esa dirección en EE.UU. con Diana de Armas (The Quixote, the Novel and the New World, 2000) y George Mariscal, presidente de la Cervantes Society of America, quien reseñó el libro para Cervantes 22, 1 (2002):

Diana de Armas Wilson decidió transportar a Cervantes y sus escritos al Nuevo Mundo y, lo que es aun más importante, situar al Nuevo Mundo en la realidad literaria y política de la España de Cervantes. (p. 172; la traducción es mía) ${ }^{8}$

Este cervantismo lleva un siglo, muestra Luis Correa-Díaz en su reciente antología. Roberto González Echevarría analizó la picaresca cervantina a la luz de las relaciones de hechos de Indias; Margarita Zamora vio en el Inca al traductor/comentarista/escritor, y en su obra de lingüista y hermeneuta, a una predecesora de la cervantina; en de Armas, la «hibridez» es el principio

7. Febres Cordero, Tulio, Don Quijote en América o la cuarta salida del ingenioso hidalgo de La Mancha (1905) [en línea], Universidad de Los Andes (Mérida), disponible en «www.walc3.ula.ve/db/ ssaber/Edocs/monografias/dependencias/viceacademico/don_quijote». Henríquez Ureña, Pedro, «De la nueva interpretación del Quijote», en «Don Quijote»: Meditaciones hispanoamericanas, Frederick Viña (ed.), Maryland, UPA, 1988. Parra, Teresa de la, Ifigenia, Caracas, Monteávila, 1977. Para la escritura "subalterna», la referencia obligada es la profesora Spivak, de India. Spivak, Gayatri, "Can the Subaltern Speak?», en Marxism and the interpretation of Culture, Cary Nelson y Larry Grossberg (eds.), Chicago, University of Illinois Press, 1988, pp. 271-313.

8. La obra de Armas provocó el grito lascasiano de Daniel Eisenberg, «[es un libro] imperialista porque trata del Imperio español, en primer lugar», traduzco de su reseña del Bulletin of Hispanic Studies (80, 2003, pp. 130-131), a la vez que el rechazo sistemático y exhaustivo de Héctor Brioso Santos, catedrático de Cervantes en la complutense de Alcalá («Novela, poliglotismo y americanismo: los poderes de la ficción o el nuevo cervantismo americano», Quaderni Iberoamericani, 98, 2005, pp. 5-32). En su reseña, Brioso le criticó a de Armas su osada incursión en áreas y temas con los que, según Brioso, ella no puede lidiar, entre otras razones por sus deficiencias en metodología y por sus opciones bibliográficas inquietantes. Investigador sólido y metodólogo impecable, Brioso co-publicó Cervantes y América (Madrid, Marcial Pons, 2006), un atinado repaso de las imágenes y tópicos de América (el indiano poco de fiar, etc.) en la obra cervantina y del muy estudiado tema del impacto de Cervantes en las Américas; lo hizo junto a José Montero Reguera, autor de «La recepción del Quijote en Hispanoamérica; siglos XVII al XIX», CHA0, 500, 1992, pp. 133-140. 
activo de la novela; Mary Gaylord alude a las «dimensiones transatlánticas» del Quijote; para Carlos Fuentes, «La Mancha es Indias»; Guillermo Cabrera Infante habló de Sancho Pampa; Alejo Carpentier («Todo está ya en Cervantes») sintió la raíz de la narrativa hispanoamericana ${ }^{9}$. En su edición cuatricentenaria del Quijote, la Real Academia Española, confirió por fin legitimidad al cervantismo americanista al promulgar:

[En 1605] salieron para América cientos de ejemplares de la novela [...] así comenzó el Quijote su andadura americana. Lo que no había conseguido Cervantes, lo lograba su criatura asentándose en el Nuevo Mundo. (La RAE citada por Correa-Díaz en la introducción de su Cervantes y América, 25) Con Don Quijote de Indias aspiro a que se considere al ámbito entero del referente hispano y no sólo a España, patria del Quijote y base de la que debe partir cualquier exploración ${ }^{10}$.

Cervantes agregó actualidad americana al Relato del Cautivo, por medio de un Oidor que «iba proveído» a esa «Audiencia de Méjico» que canta Bernardo de Balbuena en 1604:

[...] una Audiencia real, espuela y freno

de la virtud y el vicio, claustro santo, si es santo lo que sumamente es bueno. (Grandeza mexicana 102) $)^{11}$

Cervantes buscaba mecenas; dedica el Quijote I a Alonso López de Zúñiga, primo del virrey Gaspar Zúñiga, el cual pasaba del trono de México (15951603) al de Perú (1603-1606).

9. Carpentier, Alejo, discurso, Premio Cervantes, 1977; González Echevarría, Roberto, «The Life and Adventures of Cipión: Cervantes and the Picaresque», Diacritics, 10, 1980, pp. 15-26; Zamora, Margarita, Language, Authority, and Indigenous Culture in the "Comentarios reales de los Incas», Cambridge, Cambridge University Press, 1988; Mariscal, George, Contradictory Subjects: Quevedo and Cervantes in 17th-Century Spanish Culture, Ithaca, Cornell University Press, 1991; Cabrera Infante, Guillermo, discurso, Premio Cervantes, 1997; de Armas Wilson, Diana, The Quixote, the Novel, and the New World, Oxford, Oxford University Press, 2000; Gaylord, Mary M., «Mary M. Gaylord propone una lectura americana del Quijote», El País, 1/7/2003; Fuentes, Carlos, «Carlos Fuentes defiende en Berlín a la novela», Letralia 23/9/2005; Correa-Díaz, Luis, Cervantes y América. Cervantes en las Américas. Mapa de campo y ensayo de bibliografía razonada, Kassel/Barcelona, Reichenberger, 2006.

10. El presente artículo es versión modificada del capítulo primero de mi manuscrito Don Quijote de Indias, en busca del editor o editora que «llegará» a hacerlo libro.

11. Balbuena niño fue llevado por su padre, un oidor, a México; allí publicó Grandeza mexicana, dedicado a una parienta de Medina Sidonia («[de] Guzmán hecho un injerto/al Sandoval, que hoy sirve de coluna/al gran peso del mundo y su concierto»); de vuelta a la Corte madrileña la enteró de que la mexicana estaba a la espera de un virrey-mecenas: "Volverá el siglo de oro al mismo paso/ de su venida, y en virtud y ciencia/su Apolo gozará nuestro Parnaso». Elogiado por Lope de Vega, Balbuena fue autor de Siglo de oro en las selvas de Erífile y del Bernardo, cuyo destinatario fue el conde de Lemos, mecenas de Góngora y de Cervantes. De Grandeza Mexicana utilizo la edición de Porrúa (México, 1985). 
Indias era el foco financiero: entre 1604-1605 se decidía el negocio del «asiento» ${ }^{12}$; regía la Casa de Contratación Medina Sidonia el mayor propietario de esclavos (Labrado); su monopolio se transvasa al «monipodio» de Rinconete y Cortadillo, dijo Carroll Johnson ${ }^{13}$.

Por todas partes la cudicia a rodo, que ya cuanto se trata y se pratica es interés de un modo o de otro modo.

Este es el sol que al mundo vivifica; quien lo conserva, rige y acrecienta, lo ampara, lo defiende y fortifica.

(Grandeza Mexicana, 65)

El «sol» del metal precioso inauguraba la era «solar» de Lerma y su yerno Medina Sidonia:

[...] tanto por sus méritos quanto por la privanza, es con mucha prosperidad, comparado al Sol: cuyos efectos son: vivificar, engendrar, resplandecer, y estar en lugar alto y eminente. (Dedicatoria al Privado Lerma, del libro de emblemas de Hernando de Soto, 1599, citado por Harry Sieber $)^{14}$

En el segundo siglo áureo, el XVII, los caballeros castellanos periclitan, como lo sabe el criollo Balbuena, criado en una audiencia mexicana e insinuante ante la Corte española:

México al mundo por igual divide, y como a un sol la tierra se le inclina $\mathrm{y}$ en toda ella parece que preside.

¡Oh ciudad rica, pueblo sin segundo! (79)

[...] si a los oídos de los príncipes llegase la verdad [...] sin los vestidos de la lisonja [...] otras edades serían [...] [pues] de las que ahora se usan es la dorada. (Quijote II, 2)

¡Oh perpetuo descubridor de los antípodas [...] Febo allí, tirador acá [...] tú que siempre sales y aunque lo parece nunca te pones! A ti digo, ;oh sol!,

12. Era la concesión exclusiva de la trata americana; ver José Luis López Cortés, «Don Miguel, el Quijote y los negros», Mundo negro. Revista de los misioneros combonianos, 22/6/2004; Izquierdo Labrado, Julio, «El comercio de esclavos: Gibraleón [Huelva]» [en línea], disponible en 〈http://www. mgar.net/var/esclavos.html».

[Escójala] hacia la marina, porque, si no me contentare la vianda, pueda embarcar mis negros vasallos y hacer dellos lo que ya he dicho. Y vuestra merced no se cure de ir por agora a ver a mi señora Dulcinea, sino váyase a matar al gigante, y concluyámos este negocio, que por Dios que se me asienta que ha de ser de mucha honra y de mucho provecho. (Quijote, I, 29; mi énfasis)

13. Johnson, Carroll B., «The Old Order Passeth, or Does It? Some Thoughts on Community, Commerce, and Alienation in Rinconete y Cortadillo», en On Cervantes. Essays for L. A. Murillo, James A. Parr (ed.), Newark, Juan de la Cuesta, 1991, pp. 85-104.

14. Sieber, Harry (estudio y ed. crítica), Relaciones de las cosas sucedidas en la Corte, desde 1599 hasta 1614, escritas por Luis Cabrera de Córdoba, [en línea], disponible en 〈http://users.ipfw. edu/jehle/cervante/csa/articf98/sieber.html>. 
con cuya ayuda el hombre engendra al hombre! a ti digo que me favorezcas, y alumbres la escuridad de mi ingenio [...] que sin ti, yo me siento tibio, desmazalado y confuso. (Quijote II, 45)

De Sevilla a Valladolid, Cervantes tuvo oportunidad de familiarizarse con esta realidad bicostera del imperio hispano, las dos partes inseparables de la ecuación de la hispanidad.

En 1604, al Manco le fue comisionada por el primer cronista conjunto de España e Indias, Antonio de Herrera y Tordesillas, una relación para la Corona. Hace un siglo se le atribuyó la anónima Relación de lo sucedido en [Valladolid [...] desde el nacimiento de Felipe IV], ya que en «1620 está mencionado junto a este título el nombre de Cervantes, y [...] se alude a su autoría en un soneto atribuido a Góngora», siendo tal atribución refrendada actualmente por Alban Forcione y Francisco Márquez Villanueva (Eisenberg 34, n. $\left.{ }^{\circ} 5\right)^{15}$.

Los cervantistas han prestado escasa atención a esta relación poética que celebró al Heredero, publicada el año del Quijote I, pero sin el nombre de su autor $^{16}$. Es factible que el cronista imperial se la retuviera en el anonimato, pues eso hizo con ciertas relaciones que usaba para redactar sus Hechos de los castellanos (1601, 1615 Juan de la Cuesta): la de Francisco Cervantes de Salazar; y la de Bernal Díaz del Castillo (Historia verdadera, 1632, llegada a la Corte en 1575, y conocida por Bartolome Argensola, amigo del Manco) ${ }^{17}$.

Pues otra cosa peor dice [la Historia de Gómara] que Cortés mandó barrenar secretamente los once navíos en que habíamos venido; antes fue público, porque claramente por consejo de todos los demás soldados mandó dar con ellos a través a ojos vistas, porque nos ayudase la gente de la mar que en ellos estaba, a velar y guerrear. (Historia verdadera, cap. XVIII) ${ }^{18}$

$\mathrm{Y}$, con ejemplos más modernos, ¿quién barrenó los navíos y dejó en seco y aislados los valerosos españoles guiados por el cortesísimo Cortés en el Nuevo Mundo? (Quijote II, 8)

15. Eisenberg, Daniel, «Cervantes, autor de la Topografia e historia general de Argel publicada por Diego de Haedo», Cervantes 16, 1, 1996, pp. 32-53.

16. La primera edición del Quijote salió en Madrid, en enero de 1605, con muchas erratas debidas a la prisa (ver prólogo de Murillo). La relación anónima sobre el Heredero, en la que jugó tan interesante papel, el cronista imperial, lleva de fecha octubre de 1605.

17. Las relaciones inéditas retenidas en el anonimato por Herrera y Tordesillas en: Mayer, María E., «El detalle de una "historia verdadera": Don Quijote y Bernal Díaz», Cervantes 14, 2, 1994, pp. 93118; y, con mi apellido Sáez, en una monografía de un libro digital: Sáez, María Eugenia, «El Quijote de Indias», en En un lugar de las letras. Homenaje a los 400 años del Quijote [en línea], Letralia, 2005, disponible en 〈http://letralia.com/ed let/quijote/13.html〉. Encarcelado y desterrado, bajo cargos de traición y venalidad, el cronista Herrera es buen candidato a «autor fingido y tordesillesco [culpable de] lesa patria» (Quijote II, 70). O, al menos, debe agregársele a la larga nómina de candidatos a Avellaneda, la cual sale resumida en la edición del apócrifo realizada por García Salinero para Castalia. Este editor tiene su propio candidato, claro está, pero demuestra, con varios comentarios a lo largo de su prólogo, que no hay aún consenso en cuanto a este tema de la autoría del apócrifo.

18. Díaz del Castillo, Bernal, Historia verdadera de la Conquista de la Nueva España, edición crítica de Carmelo Sáenz de Santa María, Madrid, CSIC, 1982. La Hispania Victrix (1553) de Francisco López de Gómara fue retirada de circulación a poco de salir a la luz. 
Se debía, en parte, a que en 1574 Felipe II había ordenado un edicto que restringía a las relaciones de hechos ${ }^{19}$. Herrera y Tordesillas sólo reconoció usar como fuente la relación bernaldiana cuando fue forzado a declarar en una probanza, aclara el editor P. Sáenz de Santa María (p. xxvii), por el conde de Puñonrostro (mencionado en La ilustre fregona).

[...] que no tuviesen en sus archivos o en sus escritorios algunos papeles que deste famoso caballero tratasen [...] Si a ésta [historia] se le puede poner alguna objeción cerca de su verdad, no podrá ser otra sino haber sido su autor arábigo, siendo [...] los de aquella nación [...] mentirosos. (Quijote I, 8-9)

Los fechos del caballero moderno sobrevivían básicamente gracias a la épica americana en verso o en prosa ${ }^{20}$. Para el de La Goleta, autor del Quijote, la meta es llegar también al lector de Indias y no sólo al de la amanchegada España que en vano se afanó por dejar. En más de un sentido, el Quijote fue un encuentro entre España y América: amo y escudero salieron representados en fiestas populares de Valladolid en 1605, de la potosina Pausa en 1607, y de México en 1621 (acompañados, en los dos casos americanos, de las figuras del Interés, la Codicia, la Muerte y el Perulero), organizada ésta por el gremio de los plateros, el cual consignó los escándalos de venalidad bicostera sucedidos en 1606-160721. En Indias no duró en circulación, pese a que la mayor parte de la princeps tuvo por destino América. No se ha hallado ni un ejemplar americano. En México se le requisó uno a Mateo Alemán en 1608, al bajarse del barco (dato aportado por Germán Bleiberg ante la AIH en 1965) 22 . Mientras, en España el Quijote circulaba como risueña parodia.

El segundo siglo áureo se iniciaba muy distinto: un joven rey, distraído con loas y proyectos descabellados; una reina suspicaz del Valido; un frenesí esclavista y platero del que Cervantes tendría datos. Sabría del enorme desfalco en la Caja Real de Lima

19. Estudiado por Marcos Jiménez de la Espada, lo cita Mignolo. Mignolo, Walter, «Cartas, crónicas y relaciones del descubrimiento y la conquista», en Historia de la literatura hispanoamericana, I, Luis Iñigo Madrigal (coord.), Madrid, Cátedra, 1986, pp. 57-116.

20. Juan de la Cuesta, casa editorial de Cervantes, se especializó en obras de Indias y autores americanos. Sacó impresos: los poemas mexicanos de Gabriel Lobo Lasso de la Vega, la primera traducción del Inca (Diálogos de Amor, 1590), la edición final y completa de La Araucana (1590) de Ercilla, y El peregrino indiano (1599) de Antonio de Saavedra Guzmán. En 1605, rescató el requisado Arauco domado del chileno Pedro de Oña, publicado en Indias una década antes. Cinco épicas americanas salen de la imprenta del Quijote hacia la misma década, aparte de la obra del cronista imperial Herrera y Tordesillas.

21. Fue arrestado en diciembre de 1606, el oidor del Consejo de Indias Alonso Ramírez del Prado como cómplice de Pedro Franqueza, «reformador» de las finanzas reales protegido de Lerma, arrestado en Madrid en enero de 1607. Consignó ambas noticias Antonio de León Soto en sus Anales de un platero del siglo XVII (1588-1622) [en línea], disponible en 〈http:/gremios.ih.csic.es/leonsoto/ index.php?option $=$ com_content\&task=view\&id=73\&Item .

22. Bleiberg, Germán, «Nuevos datos biográficos de Mateo Alemán», en Actas del 2. ${ }^{\circ}$ congreso de la Asociación Internacional de Hispanistas (1965), Jaime Sánchez Romeralo y Norbert Polusen (eds.), Holanda, Universidad Católica de Nijmeggen, Janssen, 1966, pp. 1-26. 
- Si yo te hubiera de pagar, Sancho — respondió don Quijote-, conforme lo que merece la grandeza y calidad deste remedio, el tesoro de Venecia, las minas del Potosí fueran poco para pagarte [...] pon el precio a cada azote $[\ldots]$.

—Ellos —respondió Sancho- son tres mil y trescientos y tantos [...] que a cuartillo cada uno [...] montan tres mil y trescientos cuartillos, que son los tres mil, mil y quinientos medios reales [...]. Estos desfalcaré yo de los que tengo de vuestra merced. (II, 71; énfasis añadido)

(reformada en 1605, bajo Zúñiga), pues, como investigó Palma, se carteaba con su «amicísimo» Juan de Avendaño, quien trabajaba allí y quería traerse a Cervantes al Perú:

Así, cuando en 1606 tenía ya el Quijote lectores en Lima, Avendaño daba noticias personales sobre el autor, agregando que no le sorprendería verlo de repente por acá, pues lo animaba para que viniese a América en pos de fortuna más propicia que la que lograba en la madre patria.

(el plan se frustró debido, probablemente, a que en febrero de 1606 murió Zúñiga). Como soldado/administrador se indignaría ante la venalidad, y hace al soldado Viedma denunciar:

Perdióse, en fin, la Goleta [...] Pero a muchos les pareció y así me pareció a mí, que fue particular gracia y merced que el cielo hizo a España en permitir que se asolase aquella oficina [...] de maldades, y aquella [...] esponja y polilla de la infinidad de dineros que allí sin provecho se gastaban [...]. $(\mathrm{I}, 39)$

Sabría de la corrupción fiscal en América, ya que aspiró al cargo de contable en Nueva Granada - y a otros cargos en los virreinatos peruano y mexicano- y estaría al tanto por medio del trato con gente informada ${ }^{23}$. Las noticias volaban de América a España, dice la investigadora mexicana

23. Dos posibles informantes: el historiador Luis Cabrera de Córdoba, del Viaje del Parnaso («es de la historia conocido dueño[...]y en discursos discretos tan discreto»), escribió Relaciones de la Corte, inédita en su tiempo (Sánchez Alonso); el poeta cortesiano Gabriel Lobo Lasso de la Vega, autor de la inédita Relación puntual de las rentas del rey de España (Sánchez Alonso 494), fue, según Marcel Bataillon, el autor de los versos de cabo roto del Quijote I y quien, bajo el mecenazgo de los Zúñiga-Cortés, le sugirió dedicárselo al duque de Béjar. Este no era del corrupto círculo de Lerma (estudio de Sieber del patronato, 90). Sieber, Harry, «The Magnificent Fountain: Literary Patronage in the Court of Phillip the III», Cervantes 18, 2, 1998, pp. 85-116. Sánchez Alonso, Benito, Fuentes de la historia española e hispanoamericana, I, 3 vols., Madrid, Centro de Estudios Históricos/Junta para la Ampliación de Estudios, 1927. Otra fuente de información surgiría del nexo familiar (estudiado por Riva-Agüero):

Andrea de Cervantes Saavedra [...] contrajo tercer matrimonio hacia 1590 con el general D. Álvaro de Mendaña, de estirpe gallega, homónimo y pariente próximo del célebre navegante, sobrino del gobernador del Perú D. Lope García de Castro. Nuestro adelantado Mendaña, el descubridor de las islas de Salomón y de las Marquesas, el cercano deudo del marido de doña Andrea, fue casado con la heroica [navegante peruana, la almiranta] Isabel Barreto.

Riva-Agüero, José de la, Cervantes, Obras completas III, Lima, PUCP, 1963, pp. 5-16. 
Margarita Peña en Literatura entre dos mundos ${ }^{24}$. En 1607 fue arrestado por venalidad el reformador de las finanzas reales, Pedro Franqueza, favorito de Lerma, y poco antes Alonso Ramírez del Prado, oidor del Consejo de Indias (Elliott, 299) ${ }^{25}$. El escándalo cruza el océano en el «Cartapacio Poético» que en 1612 se trajo de México a Sevilla Mateo Rosas de Oquendo, ocultando documentos sobre la corrupción administrativa entre poemas de americanos y de españoles (Peña 109) — Cervantes incluido entre poetas-.

Un segundo siglo de oro comenzaba. Llenaban los corrales las comedias de Lope y éste servía de prologuista a El peregrino indiano (1599) del ignoto criollo Saavedra Guzmán, deudo de Medina Sidonia. Al pasar revista a su medio siglo de vida y su huella en la memoria de las gentes, Cervantes se veía casi sexagenario y con una sola obra literaria producida hacía veinte años: la pastoril Galatea. Como a «estropeado Español», le citaba la Topographia de Argel, que languidecía en galeras. Sus obras conmemorativas tampoco le habían servido para sacar su nombre a la luz pública con honra. Vivía rodeado de las audaces mujeres de su familia, a quienes poco intimidaba la nobleza de un supuesto pretendiente o la maternidad en soltería, como tampoco buscarse en la cuarentena y sin dinero un tercer marido, ni el rigor de un tribunal ${ }^{26}$. Añádase el interés del Manco por lograr algún cargo indiano, más su entrenamiento como escritor, y podrá deducirse que estuvo imbuido en la escritura documental - la cual signó el ascenso y desplome de su familia, una de hombres y mujeres de gran decisión y valor, orgullo y humor-.

El Quijote se dirige al lector hispano de ambas costas y le invita a configurar la presencia del primer imperio transoceánico de la Edad Moderna, ámbito hispano que se extendía sobre el orbe. El Relato escenifica la dinámica sociohistórica del imperio. Miguel había podido contemplar el modo en que la creación de riqueza monetaria y cultural se iba desplazando de la península ibérica a los virreinatos, en un proceso gradual pero decisivo, dominado por la Grandeza y el crédito bancario. Eran tiempos de la nueva caballería, de Don Dinero, de los trajines plateros y la Banca de la Cueva ${ }^{27}$. Los frutos de un escritor solían terminar, cuando no en el escritorio del cronista real, en manos de algún escribano de una Audiencia. Una historia «gallarda» y «mo-

24. Peña, Margarita, Literatura entre dos mundos, México, Equilibrista/UNAM, 1992.

25. Elliott, John H., Imperial Spain, 1469-1716, New York, Mentor, 1966. Hijo del oidor y, como éste, miembro del Consejo de Indias, Lorenzo Ramírez del Prado (el del Viaje del Parnaso), tuvo una de las mayores bibliotecas privadas de España según la describe ca. 1610 León Pinelo en Epítome de las Indias (Sáenz de Santa María, p. xviii). La biblioteca de Prado es estudiada por Edward Baker en La biblioteca de don Quijote (Madrid, Marcial Pons, 1997), libro reseñado por Vicente Pérez de León para Cervantes 19, 1, 1999, pp. 142-145.

26. Las Cervantes supieron litigar con éxito por generaciones, como descendientes del licenciado Juan de Cervantes, oidor del duque de Sessa; una tía paterna de Miguel le ganó costoso pleito a su ex-amante, Mendoza, hijo del duque del Infantado.

27. Lohmann Villena, Guillermo, Plata del Perú, riqueza de Europa. Los mercaderes peruanos y el comercio con la metrópoli en el siglo XVII (2004); reseñado en Identidades [en línea], disponible en 〈http://www.editoraperu.com.pe/Identidades/90/resenas.asp〉. Suárez, Margarita, Desafíos transatlánticos. Mercaderes, banqueros y el estado en el Perú virreinal, 1600-1700, Lima, Pontificia Universidad Católica del Perú/FCE, 2001. 
derna» podía quedar «manca y estropeada [...] oculta o consumida» $(\mathrm{I}, 9)$ en un archivo - realidad fantasmagórica, como la de los manchegos molinos-a menos que la protegiera un alto eclesiástico, un oidor, o que se la incluyera en un poema, o se la trasportara dentro de un cartapacio y así remontara el mar hasta el Potosí como Clavileño (II, 40). Clave entre los personajes del Quijote es el Oidor que se lleva a México la verdadera historia de un hidalgo desdichado de «humor extraño».

En mi opinión, el sentido del episodio de los Viedma, en cuanto a la orientación final de su significación, es americano. El componente magrebí, si bien decisivo para moldear al Relato, representa una etapa intermedia, la propiamente narrativa, y no la final en la que éste adquiere un contexto actualizado y casi documental. Parto de la hipótesis de Murillo del UrQuijote. Sin embargo, él se enfoca hacia lo nordafricano y en esto le guarda respetuosa distancia mi enfoque: hacia lo americano. El Relato, una relación de hechos sobre Argel, era con Oidor que había de llegar a Indias ${ }^{28}$. En «De cómo vino a México don Quijote», dijo Luis González Obregón, miembro de la Academia de la Lengua, director de la Academia Mexicana de la Historia y del Archivo General de la Nación, cronista vitalicio de la Ciudad de México y director de las publicaciones de la Biblioteca Nacional de México:

[...] uno de los pocos ejemplares que circulaban aquí en el primer tercio del siglo XVII pertenecía a un Oidor de la Real Audiencia de la Nueva España, el cual se hacía lenguas en elogio del Quijote, siempre que en los ratos de ocio charlaba con su excelencia el virrey y sus colegas los oidores. (Citado en la introducción de El Quijote en América, antología compilada por Valero Juan $)^{29}$

Sustenta al experimento narrativo del Relato del Cautivo la faceta autobiográfica. Por décadas, antes de hacerse famoso, Miguel escribió documentos, solo o en conjunto. Redactó en equipo una relación poética a la difunta reina Isabel Valois, un memorial de cautiverio y una Información de Argel (1580); e hizo por su cuenta, aparte de varias relaciones como avituallador de la Armada, dos memoriales con los que intentó pasar a Indias con un puesto, y quizá otra relación poética sobre un suceso de la familia real hacia 1612 (ver

28. La obra de Lope se introdujo en Indias por medio de un oidor del Perú, el vasco Juan de Villela, miembro del Consejo de Indias (1612-1618), estableció Irving Leonard (Los libros del conquistador). A Villela, deudo del Juan de Avendaño Villela «amicisimo» de Cervantes, le dedicó Parnaso Antártico (Sevilla, 1608) el poeta Diego Mexía Fernangil, oidor de Lima que tenía tratos comerciales con los libreros Sarria de Alcalá y Perú, quienes importaron el Quijote a Indias (cuestión que investigó Guillermo Lohmann, «Huellas renacentistas en la literatura peruana del siglo XVI», compilador Teodoro Hampe Martínez, La tradición clásica en el Perú virreinal, Lima, Fondo Editorial, 1999). Las ricas audiencias americanas tenían considerable influencia cultural en España.

29. Su opinión fue tildada de «superchería» por Francisco Icaza en «Una superchería manifiesta: De cómo fue a América el primer ejemplar del Quijote», Errores y supercherías cervantinos, Madrid, Renacimiento, 1917. Ex-condiscípulo de Obregón, se exilió en España tras la Revolución, fue elegido a la Academia Española de la Historia y murió en Madrid. 
Elías Rivers en el festschrift en honor a Murillo editado por James A. Parr) ${ }^{30}$. Pocos meses antes de dar a luz el Quijote, escribió la antecitada relación encargada por el cronista imperial Herrera y Tordesillas y publicada como de autor anónimo. La versión sucinta de la participación del Manco en la defensa de Túnez tampoco saldría a la luz hasta 1612, con la Topographia de Argel de Haedo, aunque se perfila en el Relato del Cautivo. Su obra está signada por la multiautoría, el anonimato y la circulación tardía en versiones.

Pasaban las décadas, se gestaba a trompicones el Quijote, y Cervantes se iba enajenando del texto sin querer escribir más sobre su manchego, se iba cansando de ir de sitio en sitio para ganarse la vida, de redactar documentos sobre el mijo y el trigo, de buscar reconocimiento como veterano de guerra o como escritor, de intentar pasar a Indias o, al menos, informarse de ellas. Se acercaba de nuevo al Relato, iba dando con la clave para la redacción final del Quijote: el oidor que parte a Indias es el nuevo caballero, el del cambio de vuelta de siglo, el antipolo de Don Quijote, quien es el verdadero cautivo.

El Relato del Cautivo es el episodio axial del Quijote I. Sus etapas de elaboración sirven para analizar las del texto. Presento ahora mi retrospectiva sobre estas etapas, las cuales, si no yerro, fueron tres. La primera hubo de ser un parco informe militar del soldado Saavedra sobre el Magreb, o un conciso memorial de servicios sobre su gestión y cautiverio - como el que hizo en 1582 - en vez de una relación de hechos. La intermedia, la etapa narrativa, con la inclusión de los amores entre el cautivo y la mora (capítulos 39-41), fue una relación de hechos que, según Murillo, circuló hacia 1590. La etapa última añade a la anterior los varios capítulos que incluyen al Oidor (42-47) hacia el final del Quijote de 1605. Baso la alta probabilidad de mi hipótesis en las razones que siguen.

El Manco, recién rescatado de Argel en 1580 y discapacitado para seguir la carrera militar, redactaría la primera versión de su cautiverio al estilo parco de su Información de Argel, enviándola a algún personaje influyente hacia 1582 - ese año solicita un puesto en Indias en carta a Antonio de Eraso, secretario del Consejo de Indias, quien despeja el imprimatur de La Galatea (1585). Era el paso lógico a dar de parte de un recién liberado que aspiraba a una sinecura ligada al procesamiento de documentos:

Perdióse, en fin, la Goleta; perdióse el fuerte, sobre las cuales plazas hubo de soldados turcos, pagados, setenta y cinco mil, y de moros y alárabes de toda la África, más de cuatrocientos mil [...] Fue común opinión que no se habían de encerrar los nuestros en la Goleta, sino esperar en campaña al [desembarco; mas] lo que esto dicen hablan de lejos y con poca experiencia de casos semejantes; porque si en la Goleta y en el fuerte apenas había siete mil soldados, ¿cómo podía tan poco número, aunque más esforzados fuesen, salir a la campaña y quedar en las fuerzas, contra tanto como era el de los enemigos? $(\mathrm{I}, 39)$

30. Rivers, Elias, «Genres and Voices in the Viaje del Parnaso», On Cervantes, 208. 
Al no rendirle el informe el resultado esperado, pasó a narrativizarlo como relación de hechos, desplazando el enfoque desde lo español y militar hacia el Magreb y su cultura sincrética de musulmanes, judíos y cristianos ${ }^{31}$. La parte creativa del Relato consiste en los afanes de Zoraida y del capitán que quiere ayudarla a hacerse cristiana una vez escapen. El recuento adquirió ligereza, amenidad e interés sentimental. Era necesario darle al tema un nuevo giro, reabordar el cautiverio. El fracaso de la Armada y las incursiones de Francis Drake en suelo ibérico indujeron a los escritores españoles a poner en segundo plano la gloria militar de España. Para 1590, ya la fuga de la pareja estaba integrada al Relato:

[...] sacaron por la mesma ventana una pequeña cruz hecha de cañas, y luego la volvieron a entrar. Esta señal nos confirmó en que alguna cristiana debía de estar cautiva en aquella casa [...] pero la blancura de la mano y las ajorcas que en ella vimos nos deshizo este pensamiento [...]. (I, 40)

El Quijote de 1615 ofrece comento sobre esta narración amena y artificiosa del cautiverio la cual dio a algunos lectores de la época la impresión de no encajar bien:

[...] había usado en la primera parte del artificio de algunas novelas, como [...] la del Curioso impertinente y la del Capitán cautivo, que están como separadas de la historia, puesto que las demás que allí se cuentan son casos sucedidos al mismo don Quijote, que no podían dejar de escribirse. (II, 44)

El Manco dejó integrada, hacia fin del XVI, esta narración de la cautividad en sus componentes principales - el informe militar, más los legendarios relatos de amores berberiscos. Pero aún no había terminado el proceso de hibridación al que la sometería. La circunspección adquirida tras sus avatares en Sevilla y Valladolid - el cambio tremendo que inauguraron el corrupto Valido y su yerno del monopolio - surtió efecto en la última redacción del Quijote. Incluyó en el Relato al oidor indiano con un papel prominente. El resultado fue un curioso episodio argelino-manchego, pero de orientación americana.

Acuciado por sus desvelos monetarios, Cervantes, desde su juventud escritor de relaciones en prosa o verso, aprendió en sus postrimerías a no despreciar ninguna de sus facetas de escritor. Las integró en torno a un testimonio no sólo de su propia participación en un hecho histórico - como actor y autorsino del poder que tiene un texto/documento para moldear la percepción de la «realidad», y una como la hispana que rebasaba océanos, razas, credos y calendarios. El vocablo «realidad» es empleado por el Inca, en el prólogo a sus Comentarios reales (1609), al hablar de los «orígenes fabulosos» de ésta ${ }^{32}$.

31. Cervantes trató con la familia de un ex-cautivo en Berbería, F. Jerónimo Gracián, colaborador de Santa Teresa expulsado del Carmelo, cuya obra manuscrita circuló en 1601. Gracián, Gerónimo, Peregrinación de Anastasio. Diálogos de las persecuciones, trabajos, tribulaciones y cruces sufridas [...] [1614], Burgos, Monte Carmelo, 1905.

32. Avalle-Arce, Juan Bautista (ed.), El Inca Garcilaso en sus Comentarios. Antología vivida, Madrid, Gredos, 1964. 
La «realidad» socio-histórica era representada por medio de tres tipos de escritura y el Relato los despliega: desde el más inaccesible (el documento privado); al medianamente asequible al lector y aceptable al poder (el pliego suelto o la literatura de cordel); al que adquiere existencia concreta cuando circula al amparo de las autoridades (el texto que va a ser impreso). En el Quijote, estos tres corresponden a: 1) la mención de que se han omitido «hechos» del soldado Saavedra; 2) el relato del cautiverio argelino que el capitán cuenta a los presentes con la fórmula de amores, al que el cura añadirá el indispensable toque de ortodoxia; 3) la historia de «humor extraño», la cual llevará a Indias el Oidor.

Se fue gestando, de la garganta a la mano de Cervantes, un texto oral con vocación de impreso, contado y leído tantas veces, dirigido allende el océano. Hay curas que hallan historias y oidores que se las llevan de parte a parte del imperio. El veterano de La Goleta al que su hermana Andrea Cervantes describió, el verano de 1605, ante el tribunal que juzgaba el caso del caballero Ezpeleta, como «hombre que escribe y hace negocios e por su habilidad tiene amigos» (Canavaggio, 38), deja oír en España y América que no está solo ni aislado ni desvalido ${ }^{33}$. Le aguzan el oído los encumbrados intrigantes. El futuro plagiario dirá en su prólogo: «en los medios diferenciamos, pues él tomó por tales el ofender a mí, y particularmente a quien tan justamente celebran las naciones más extranjeras [Lope]».

En el Relato del Cautivo, Cervantes hace converger su trayectoria de escritor de ficción con la de escritor de documentos de tema norteafricano. El capitán Ruy Pérez de Viedma cuenta de las prisiones de Argel, pero a la vez enfatiza que omite algo «mejor»:

[Y] si no fuera porque el tiempo no da lugar, yo dijera ahora algo de lo que este soldado [Saavedra] hizo, que fuera parte para entreteneros y admiraros harto mejor que con el cuento de mi historia. (I, 40)

Esta mejor «parte» no podía dejar de mencionarse, como sugirió Haedo a vuelta del 1600

[...] y del cautiverio, y hazañas de Miguel de Cervantes se pudiera hacer una particular historia. (Topographia de Argel [Valladolid, 1612; la primera aprobación es de 1604]; capítulo «De los Martyres», 185)

en una obra que no pudo salir a la luz sino hasta la década siguiente, cuando en su segunda aprobación se estampara la firma del cronista real Herrera y Tordesillas, el gran supresor de historias «modernas» de Indias (las de Bernal Díaz, Francisco Cervantes de Salazar et al.). Para que sus apellidos de autor y veterano, Cervantes Saavedra, subsistieran en una sociedad asomada al comercio americano y a los chanchullos virreinales de los Grandes, el que una vez creyó que por sus «armas y letras» podía triunfar, fue reescribiendo

33. Canavaggio, Jean, «Aproximación al Proceso Ezpeleta», Cervantes, 17,1, 1997, pp. 25-45. 
el Relato, según iban cambiando sus circunstancias personales, a lo largo de tres décadas.

«Armas y letras». Con el discurso del imbatible narrador Don Quijote interrumpido en la venta, el de La Goleta se desdobla en escritor a fin de mostrar el cisma irresoluble, y deja el tajo final a la pluma nupcial de Cide Hamete: «él supo obrar y yo escribir».

Cuando Andrea atestigua que Miguel es «hombre que escribe», se refiere también al que desde joven fue escritor de documentos y ahora salía del olvido con un quejoso libro:

Quieren decir que tenía el sobrenombre de Quijada o Quesada [aunque] por conjeturas verosímiles se deja entender que se llamaba Quejana. (I, 1)

[R]espondió don Quijote-; y si no me quejo del dolor es porque no es dado a los caballeros andantes quejarse de herida alguna [...].

- Si eso es así, no tengo yo que replicar — respondió Sancho-; pero sabe Dios si yo me holgara si vuestra merced se quejara cuando alguna cosa le doliera. De mí sé decir que me he de quejar del más pequeño dolor que tenga, si ya no se entiende también con los escuderos de los caballeros andantes eso del no quejarse. (I, 8; énfasis añadido)

Francisco Rico notó que en la princeps del Quijote figuraba "Quexana» y que la segunda tirada parcial de Juan de la Cuesta lo cambió a «Quijana [...] por error»; en la segunda edición del Quijote se alterna el apellido entre Quijana-Quejana ${ }^{34}$.

El año de la relación comisionada por Herrera y Tordesillas, se inicia la «serie» de Don Quijote (tres, si se cuenta el apócrifo) y marca el último escarceo del escritor de documentos, el cabo de una maraña de notarías, el fin de una gran andanza en pos del reconocimiento. El Quijote se presenta como texto sin centro ni autor único: se cambian nombres, se multiplican «autores», se hallan y transcriben manuscritos, circulan varias versiones, destacándose entre todas la que se ha suprimido, la del propio Saavedra:

[...] sin osar estenderse a otras digresiones y episodios más graves y más entretenidos [...]. Y así, en esta segunda parte no quiso ingerir novelas sueltas ni pegadizas, sino algunos episodios que lo pareciesen nacidos de los mesmos sucesos que la verdad ofrece [...] [dice la parte de 1615].

La «historia» - de peregrina liberación- que el texto teje y desteje ante el lector es la de un mundo hispano ultramarino, que se descubre en la venta por medio del Oidor.

34. Rico, Francisco, «Nota sobre las dos primera y posibles erratas de la princeps en relación con el cambio en la segunda tirada parcial de Juan de la Cuesta, y las que la siguen, que cambian Quexana a Quixana», Cervantes (1996), edición especial, Anuario bibliografico cervantino 1994-95, 1034. Mi interpretación del «que escribe» de Andrea no es la habitual, para la cual sugiero consultar el premiado libro de Juan Carlos Rodríguez, El escritor que compró su propio libro: para leer El Quijote, Barcelona, Debate, 2003. 
Valga ahora un caveat. El centrarnos en el Relato como origen del Quijote no equivale a reducir toda la lectura a un único episodio, limitación contra la cual nos alertó Howard Mancing con su «principio de los molinos de viento» del mundo caballeresco de Don Quijote ${ }^{35}$. Pero sí equivale a afirmar esto: el Relato detenta una función axial en un texto de vocación indiana y voz des-autorizada, es decir, sin autoría ni autoridad claras, un texto destejido en «voces». Tejido de prosa, saga o serga, es presentado como sobreviviente de sorpresas y fatigas, un texto de vocación tránsfuga que a duras penas mantiene su unidad, macerado en temas diversos y desdibujado como el de la Triste Figura. Para mantener una mínima cohesión como narrativa, necesita de un eje. Y éste es el Relato del Cautivo.

El Ur-Quijote fue depurado en etapas sucesivas, hasta llegar al encuentro con el Oidor, pero al pasar de una a otra se mantuvo como relato axial. En el Relato, como si en una encrucijada, se ensarta el plano de la actividad escriturial de Cervantes con el de su pasado de soldado. Intersección de las escrituras de ficción y documental, toque auto-biográfico incluido, el Relato del Cautivo es eje del Quijote no sólo por su tema - la contraposición entre el caballero periclitado y el caballero indiano- o por servir de matriz a las etapas de elaboración, sino por una razón adicional: porque está desapegado del texto, «como separad[o] de la historia» dice el prólogo a la parte II, en una nota crítica.

Cervantes, actor en «aquella facción prodigiosa» de Lepanto, contratacará, en el prólogo a la parte II, al «autor del segundo Don Quijote, digo, de aquel que dicen que se engendró en Tordesillas y nació en Tarragona» (prólogo del apócrifo); se defenderá de esa pluma tan influyente y arrogante que se antepone incluso al Fénix de los Ingenios.

Cervantes ya antes de estas fechas entendía el lenguaje del Poder suficientemente. Pero ahora, por el aventurado contacto con Herrera y Tordesillas, pudo o, al menos, tuvo la oportunidad de constatar que la relación indiana compartía una misma trayectoria con sus propios escritos, tan modernos como «estropeados». Se le replanteó entonces el tema de lo que periclita y lo que permanece, de lo que se suprime y lo que sale a la luz - cuestiones graves que moldean el conocimiento que una sociedad pueda percibir sobre su «realidad». El que la calidad conlleve garantía de permanencia apuntaló su confianza.

El Relato logra que dialoguen entre sí las variantes de la «realidad»: una encarnaba en el texto impreso que hace del dominio público el informe sobre la pérdida de La Goleta; otra correspondía a la imaginativa del pueblo adepto a leyendas moriscas y a relaciones de sucesos que circulaban ${ }^{36}$; y finalmente, in-

35. Mancing, Howard, The Chivalric World of Don Quixote. Style, Structure, and Narrative Technique, Columbia, University of Missouri Press, 1982.

36. Espoleadas por el estudio pionero del editor Henry Ettinghausen, las relaciones de sucesos - no las de hechos - vienen siendo objeto en España de un estudio sistemático liderado por María Cruz García de Enterría, Sagrario López Poza y Carmen Espejo Cala. Ettinghausen, Henry, ed., Noticias del siglo XVII: Relaciones españolas de sucesos naturales y sobrenaturales, Barcelona, Puvill, 
audita, en manos de escribanos y magistrados, yacía sepultada en escritorios la cotidianeidad de los vulnerables, desprovistos de acceso a voz que pudiera asistirles. Cervantes, veterano de armas y letras, frustrado viajero de Indias, había adquirido un saber sobrio y regocijado, y ansiaba compartirlo con sus lectores de ambas orillas, para que entendieran entre susurros las palabras nuevas de un mundo viejo en hechos, y así pusieran el pensamiento en acción y la acción en pensamiento.

Sobre el discurso de las Armas y las Letras, que interrumpe don Quijote al entrar el Oidor, decía Niceto Alcalá Zamora, ex-presidente de la II República española, en El pensamiento de El Quijote visto por un abogado (obra publicada en 1950, en Argentina):

[E]s indudable que si el autor del Quijote se hubiera propuesto plantear semejante opción entre lo bélico y lo literario, habríala resuelto a favor de lo primero [...] Pero es el caso que en el célebre discurso [...] no hay comparación entre literatos y militares, y sí de éstos con los juristas, es decir, con los abogados [...] llega el autor a plantear las relaciones entre el Derecho y la fuerza [...] y para que no quepa duda, en la venta, donde aquel [discurso] se pronuncia, vienen a coincidir el capitán cautivo [...] y su hermano el oidor Viedma, representantes del ejército y de la magistratura, no dejando lugar a duda que la simpatía está a favor de los sufrimientos del uno, y no de los encumbramientos [del otro] $(103)^{37}$.

El Oidor es un «caballero» de hoy. Del año del Quijote es La Pícara Justina. Richard Kagan hace notar que el aparato judicial español, que ya estaba sobrecargado, llegó al límite de capacidad a la vuelta del XVI, con la red de peticiones, demandas y contrademandas que hubo; a tal grado que esta novela picaresca de 1605 arranca con una versada imprecación a Dios para que los libre de leguleyos ${ }^{38}$. Extrae Kagan la conclusión de que los lectores del Quijote verían al protagonista como un ser anacrónico respecto al sistema legal imperante,

1995. María Cruz García de Enterría, Henry Ettinghausen, Víctor Infantes, Augustín Redondo, eds., Las Relaciones de sucesos en España (1500-1750), Actas del primer Coloquio Internacional (Alcalá de Henares, junio, 1995), Publications de la Sorbonne/Servicio de Publicaciones de la Universidad de Alcalá, 1996. López Poza, Sagrario. Bibliografía esencial sobre Relaciones de Sucesos [en línea], disponible en 〈http://rosalia.dc.fi.udc.es/BORESU/Bibliografia.html». Espejo Cala, Carmen, «Historia y estructura de la prensa sevillana; orígenes del periodismo en Sevilla» (curso de Doctorado) [en línea], Universidad de Sevilla, España, disponible en 〈http://www.us.es/dp/pos/prensa.html〉. Un seminario de la Universidad de Salamanca, en 1998, sobre el nacimiento del libro a partir de la «literatura efímera»se ocupó de las relaciones de sucesos. Redondo llamó la atención sobre las escasas relaciones americanas, al puntualizar que las relaciones eran el género hispano más popular y Sevilla era el «centro de "relaciones de sucesos" en torno a 1600». Gonzalo García, Consuelo (coord.), «Historia del libro III: El nacimiento del periodismo: imprenta e ideología en las relaciones de noticias de la época de los Austrias», en Valero Moreno, Juan Miguel (comp.), Seminario de estudios medievales y renacentistas 1997-1998 [en línea], disponible en 〈http://www3.usal.es/ semyr/ reuniones-actas-97-98-7.htm\#3>.

37. Alcalá Zamora, Niceto, El pensamiento de El Quijote visto por un abogado, Buenos Aires, Guillermo Kraft, 1950.

38. Kagan, Richard, Lawsuits and Litigants in Castile 1500-1700, Chapel Hill, University of Carolina Press, 1991. 
el cual se manejaba a base de oidores. En 1605 otras obras, no de ficción, tocan el tema judicial. Publica el escribano Nicolás Irolo, que pasó a México

[allí ejerció el cargo de escribano, dando a luz en 1605 [...] Política de Escripturas obra que, al decir de Beristaín, «es una pauta de escrituras legales reformando las expresiones antiguas con arreglo a la mayor cultura del idioma castellano, y con varias adiciones para casos y asuntos extraordinarios». (José Toribio Medina, «Cervantes americanista») $)^{39}$

quizá con el virrey Zúñiga en 1595. Su hijo Gabriel Ayrolo creció en casa de Zúñiga, se graduó de Leyes en México y, llegado a España, dedicó a Medina Sidonia, el benefactor o «Josef» de la familia, su Pensil de Príncipes y Varones Ilustres (Sevilla, 1617):

Es acero, Dios imán,

Que os suspende desde el cielo.

Favor es, y sin segundo

Que os hace su amor profundo

Pues sin más diferenciar,

Como en la tierra al pasar,

En el agua sois Raimundo.

Si el Egipcio hizo adorar

A Josef con tal grandeza

A vos en tan buen lugar

El que es del mundo cabeza

Con la llave os quiso honrar,

Tan grande lugar Raimundo

Os da, que él solo en el mundo

Porque representa a Dios,

Es primero, y luego vos,

Por la llave sois segundo.

composición de mundanos versos, por la que Lope le honró en el Laurel de Apolo. Irolo o Yrolo, el Viejo, era gaditano y su apellido fue quizá modificado por su hijo Gabriel ${ }^{40}$.

Estos leguleyos habrían llamado la atención a Johnson —en su etapa final le siguió el paso a la bête noire del Manco y a sus nexos con Cádiz- quien

39. Medina, José Toribio, «Cervantes americanista: lo que dijo de los hombres y cosas de América», en Manuel Alcalá y Carlos Montemayor (coords.), Apuntes cervantinos hispanoamericanos I, 2 vols., México, Edicupes, 1989-1990, pp. 17-45.

40. No salen en Astrana Marín, pero Francisco Icaza prestó atención a Nicolás Irolo:

«De los escribanos públicos en la Nueva España» en El Notariado en México a partir de su codificación (México, 1984); «La ordenación notarial en la Recopilación de Indias» en Recopilación de las Leves de los Reynos de las Indias. Estudios Histórico-Jurídicos (México, Porrúa, 1987); «Los escribanos en los señoríos de la Nueva España» en RChHD n. ${ }^{\circ} 13$ (Santiago de Chile, 1987) [...] «Nicolás de Yrolo Calar y su obra», en Cuadernos del Instituto de Investigaciones Jurídicas, año II, n. ${ }^{\circ} 4$ (México, enero-abril 1987) [...] y «Las escribanías mayores de la gobernación y guerra de la Nueva España», IV Congreso de Historia del Derecho Mexicano (México, 1988) [...] (cita de Antonio Dougnac Rodríguez, de la Academia Chilena de la Historia);

$<$ http://www.scielo.cl/scielo.php?pid $>$. 
dijo en su libro sobre el «mundo material» del Manco, Cervantes and the Material World:

El que se perdiera Cádiz no se debió, como sabemos, a los burgueses cobardes sino al aristócrata Medina Sidonia cuyos intereses en los negocios propios le resultaron de mayor peso que su jurado deber de defender el lugar [...]. Con su calculada pasividad el duque propinó un golpe inmovilizador a los burgueses gaditanos, incipientes capitalistas, y se aseguró de que el poder continuara en manos de la aristocracia. $(189,193 \text {; mi traducción })^{41}$

Johnson vislumbró en el Oidor al verdadero representante del nuevo orden económico, pero no desarrolló este aspecto clave del personaje ni su nexo con América, reseñó Mariscal ${ }^{42}$. Apuntala la crítica del de San Diego que en cada fin del Quijote medien los escribanos y/o leguleyos: en la parte I, el magistrado; y en la II, «un escribano, ante el cual alcalde pidió don Quijote, por una petición, de que a su derecho, convenía que don Alvaro Tarfe, aquel caballero que allí estaba presente, declarase [sobre la autoría del Quijote]» (II, 72) ${ }^{43}$.

El Relato del Cautivo, caps. 39-41, rebasa sus cotas. La inicial se anuncia en I, 36, con la escena de los que escuchan al cura leer la novella de la curiosidad impertinente; Luscinda interpela a Cardenio: «Vos sí, señor mío, sois el verdadero dueño desta vuestra captiva, aunque más lo impida la contraria suerte, y aunque más amenazas le hagan a esta vida que en la vuestra se sustenta». El siguiente agrega: «un pasajero entró [que] en su traje mostraba ser cristiano recién venido de tierra de moros [...]». Don Quijote ofrece un comentario más que adecuado a la situación: «¿cuál de los vivientes habrá en el mundo que ahora por la puerta deste castillo entrara, y de la suerte que estamos nos viere, que juzgue y crea que nosotros somos quien somos?» (I, 37).

[...] dicen las letras que sin ellas no se podrían sustentar las armas, porque la guerra también tiene sus leyes [...]. Y así considerando esto, estoy por decir que en el alma me pesa de haber tomado este ejercicio de caballero andante en edad tan detestable como es ésta en que ahora vivimos. (I, 38)

41. Johnson, Carroll B., Cervantes and the Material World, Chicago, University of Illinois Press, 2000.

42. Remonta la timidez de Johnson como cervantista al tabú que erigió una valla de separación entre España e Hispanoamérica, y transmitió la alarma contra la lectura novo-mundista/americanista del Quijote en el contexto económico. Insta Mariscal al cervantismo para que supere este trauma e integre el análisis global. Mariscal, George, reseña de «Cervantes and the material world» de Carroll B. Johnson, Arizona Journal of Hispanic Cultural Studies 5 (2001). En ese sentido, léase la reseña cauta y eficaz que hace Barbara Simerka de «Gustavo Illades y James Iffland (eds.), El «Quijote» desde América (Puebla, Universidad Autónoma de Puebla/El Colegio de México, 2006), [en línea], en Cervantes: Bulletin of the Cervantes Society of America, 28.2 (2008), disponible en «http://www. langinnovate.msu.edu/ cervantes/csa/articf08/SimerkaF08.pdf .

43. Tarfe, personaje del apócrifo del que se apropia Cervantes para autentificar el texto y asentar autoría, me recuerda al Luis de Córdoba que se disfrazó de don Quijote en la peruana Pausa y se encargó de que llegara allí el cargamento de los Sarria: el Quijote. 
El episodio cubre ocho capítulos al pasar del capitán Viedma a la entrada de su hermano el Oidor (del que se despide en I, 47), es decir casi entera la parte cuarta y final del Quijote I. Tras el encuentro con el Oidor, don Quijote no acometerá aventura caballeresca alguna.

En I, 44 las mujeres de la venta «se desesperaban de ver la cobardía de don Quijote», quien no quiere intervenir en la pelea de los sirvientes del hijo de un noble con los cuadrilleros de la Santa Hermandad. En I, 46 don Quijote no defiende el honor de una dama, la hija del Oidor, sino que se limita a asumir posturas y a hacer gestos teatrales ante los demás: «enarcó las cejas, hinchó los carrillos, miró a todas partes y dio con el pie derecho una gran patada en el suelo, señales todas de la ira que encerraba en sus entrañas». En el siguiente capítulo se despide el Oidor y queda el manchego enjaulado.

Se cierra en círculo la antítesis definitiva: don Quijote/Oidor. En el Quijote II es el Bachiller quien infringe la derrota final al de la Triste Figura. Es un final prefigurado en la parte I, cuando don Quijote queda «captivado» frente al que parte a una audiencia de Indias. La estructura de las dos partes del Quijote muestra el desencuentro de caballeros.

El Relato puede leerse como función de variables: la supresión de voz, la suspensión del relato, el documento rescatado, la irrupción editorial, la circulación en versiones, la mediación clave, y la impresión final. Son los rasgos del texto desgarrado, «desnarrado» ${ }^{44}$, por el escritor-bisagra que sacó al Quijote del quicio peninsular y lo abrió a América. 


\title{
Resumen
}

La primera aventura de don Quijote, el combate con el vizcaíno, y la última, en que conoce al Oidor, versan sobre «caballeros» que parten a Indias. La antítesis de don Quijote es el leguleyo que zarpa a la audiencia de Nueva España, tipo del caballero que medra durante la privacía de Lerma, a vuelta del XVI. Escucha «casos» y hace «negocios». Con él pasan a América el inesperado novio de su hija, heredero de un título, y la «historia» del «humor extraño» del manchego, transmitida por el cura que halla manuscritos anónimos. El cauto proceder del Oidor contrasta con las abiertas proclamas de don Quijote: una clave para que los habitantes del imperio leyeran el Quijote en el contexto bicostero España/Indias.

Palabras clave: Ur-Quijote. Relato del Cautivo. Oidor. Virreinatos de Indias. Virrey Zúñiga. Comercio de la Plata. Lohmann. Suárez. Johnson. Mariscal. Kagan. Armas-Wilson. Asiento. Esclavos.

Title: Don Quixote and the Auditor from México: a disagreement between a knight and a gentleman

\begin{abstract}
Don Quixote's first adventure, the combat with the Basque, and his last one, in which he meets the Auditor, both deal with a «knight»/gentleman who is leaving for the West Indies. The opposite pole of the Manchego knight is the gentleman appointed to the Audience of New Spain, $c a$. 1600, during Lerma's Privacy. This lawyer/auditor hears two «cases»: the «strange humor» of the Manchegan, as told by the priest who has found an anonymous manuscript; and the «unnexpected business» of his future son-in-law, who will accompany him to Mexico, heir to a title. The Oidor's discreet proceedings contrast with Don Quixote's open proclaims, thus serving as key to a bicostal (Spain/Indies) reading of the Quixote.
\end{abstract}

Key words: Ur-Quixote. Captive's Tale. Auditor. American Viceroyalties. Viceroy Zúñiga. Silver Trade. Lohmann. Suárez. Johnson. Mariscal. Kagan. Armas-Wilson. Asiento. Slaves. 